\title{
Practical application of bioelectric research of biologically active centers for the assessment of sheep wool productivity
}

\author{
Liudmila Samusenko, and Andrey Mamaev
}

Orel State Agrarian University named after N. V. Parakhin, Faculty of Biotechnology and Veterinary Medicine, Generala Rodina, 69, Orel, 302019, Russia

\begin{abstract}
The intensification of sheep wool production requires development of new methods for assessing the quality of products based on the knowledge of the functional state of the body, life support mechanisms and the formation of products in the process of its synthesis. Such functional systems include a complex of superficially localized biologically active centers (SLBACs) of animals, which serve as sensory regulatory formations involved in providing compensatory adaptive reactions of the animal organism. The research was carried out on sheep of the North Caucasian breed and the North Caucasian and the Romanov cross-breeds (3/4 R X $1 / 4 \mathrm{NC})$. The aim of the research was to clarify the possibility of assessing the wool productivity of sheep of different breeds according to the level of the bioenergetic potential (LBP) of their superficially localized biologically active centers. The studies were carried out on sheep of the North Caucasian breed and their crossbreeds with the Romanov breed (3/4 R X $1 / 4 \mathrm{NC}$ ). The object of the research was 6- and 8-month-old ewe hoggs and adult purebred ewes of the North Caucasian breed at the age of 2 years old. It was found out that sheep of different breeds and ages have different LBP of the SLBACs, and the value of the biopotential can be used to assess the quantitative and qualitative properties of wool in the comparable units. Based on the established dependencies, a method for determining a sheep wool classing has been developed. This method eliminates the need to use complex laboratory equipment and reduces time for the wool research.
\end{abstract}

\section{Introduction}

At the government level more and more attention is paid to ensuring the country's food security. In import substitution cases, sheep breeding plays a significant role as one of the livestock industries, providing the country's population not only with dietary food - milk and meat, but also wool and leather raw materials for the manufacturing industry [1,2].

Wool is the main product of sheep breeding and in some time it can play a leading role in meeting the needs of mankind in solving a number of socioeconomic and even environmental problems. Nowadays, North Caucasian meat, a wool-growing breed of sheep, is imported to the territory of the Orel region. It will allow the region not only to receive a sufficient amount of meat and wool, due to the pure breed breeding, but also to use it for interbreeding with the ewe of the regionalized Romanov breed, traditionally bred in the region $[3,4]$.

\section{Problem Statement}

The development of modern technologies in animal husbandry is not only aimed at its intensification, but it also uses in its practice new methods based on knowledge in the field of physiology of productive animals. Scientists and experts are looking for new biotechnological and environmentally friendly methods that allow increasing the viability of productive animals' organisms, with the diagnosis of their functional state and the management of reproductive and reparative functions. So, the use of methods of stimulation superficially localized biologically active centers of animals of different species, allows to adjust the reproductive function and to reduce the duration of technological periods [5-8]. It is possible to correct the reproduction function by influencing the biologically active centers in pig breeding: multiple pregnancies, large-fruited, nest weight [9-11]. The level of bioelectric potential of superficially localized biologically active centers can be used to assess the slaughter qualities of cattle and pigs under the conditions of transport stress, as well as to apply various effects on the biologically active centers to eliminate negative consequences of the

\footnotetext{
*Corresponding author: 1dsamusenko@ mail.ru
} 
transport stress. However, the analysis of the scientific sources did not reveal information on the use of the superficially localized biologically active centers localized on the body of sheep to assess their productive potential and product quality. In this regard, the use of bioelectric potential of the superficially localized biologically active centers seems to be a promising direction in assessing the productive potential of sheep [12]. Centers are complexly determined structural units of the organism, which, by means of neurovascular structures, unite the internal structures of the organism, to which the reflexological influence is directed. The connection of biologically active centers through the Central nervous and vascular systems allows you to control the body and its internal organs. As a result, when exposed to the centers of acupuncture methods, there is a surge and regulation of the bioenergetic potential of the body, which leads to the restoration of functional activity of dysfunctional internal organs, increases immunity and resistance of the body [13-15].

\section{Research Questions}

The increase in wool production demands a quick assessment of the quality of the resulted product using a set of new and traditional methods to be organized [4]. The new express method can be based on new knowledge about the life support mechanisms of the highly organized living systems [7, 10]. Such functional systems include a complex of the superficially localized biologically active centers (SLBACs) of animals, which serve as sensory regulatory formations involved in providing compensatory-adaptive reactions of the animal organism. The studies conducted by (Leshchukov K.A., (2017) on cattle, pigs and horses, showed that by studying the biophysical properties of the SLBACs, it is possible to assess the functional activity of individual organs and body systems of the animals (Verzhbitskaya,1961, Mamaev 2005).

80 skin-deep localized biologically active centres (SLBAC) in different anatomic zones on the sheep body surface are identified for the first time. It is established that the level of bioelectric activity of the centers ranges from 39 to $72 \mathrm{~mA}$ and they have certain histologic features. SLBAC can be used to assess functional condition of sheep organism, to study productive homeostasis, to correct the level of animals' efficiency.

The aim of the research was to clarify the possibility of assessing the wool productivity of sheep of different breed according to the level of the bioenergetic potential of superficially localized biologically active centers.

\section{Research Methods}

The studies were carried out on sheep of the North Caucasian breed and their crosses with the Romanov breed (3/4 R x 1/4 NC). The object of the research was
6- and 8-month-old ewe hoggs and adult purebred ewes of the North Caucasian breed at the age of 2 years old.

The experimental groups were formed on the basis of analogues, in accordance with the goal and objectives of the research. The experimental animals were kept in equal feeding and keeping conditions.

The following SLBACs were selected for the research: No. 13, 15, 26, 64, 65, 80. The bioelectric potentials were measured in them.

The localization and numbering of the SLBACs on the body of sheep was adopted on the basis of the research done by L.D. Samusenko, A.V. Mamaev. (2015)

The places of the SLBACs localization:

No. 13 - on the dorsomedial line of the body in the scrobiculus between the spinous process of the last lumbar vertebra and the first sacral vertebra.

No. 15 - on the dorsomedial line of the body between the spinous processes of the last sacral and first caudal vertebrae.

No. 26 - bilaterally, parallel to the dorsomedial line of the body at the level of the dorsal caudal edge of the scapula in the 6th intercostal space, counting the 13th rib cranially

No. 64 - bilaterally, caudally of the 13th rib by 1 width of the palm and 2 fingerbreadths, and dorsally BACs 63 by 2 fingerbreadths.

No. 65 - bilaterally, 1 fingerbreadth caudally of BACs 64 and 1 fingerbreadth dorsally BACs 64 .

No. 80 - bilaterally, 2-4 of the fingerbreadths below the medial border of the stifle joint and 1-2 of the fingerbreadths from the lateral side of the shinbone caudally .

The localization of SLBACs is clearly shown in Figures 1, 2. (Patent No. 2570325)

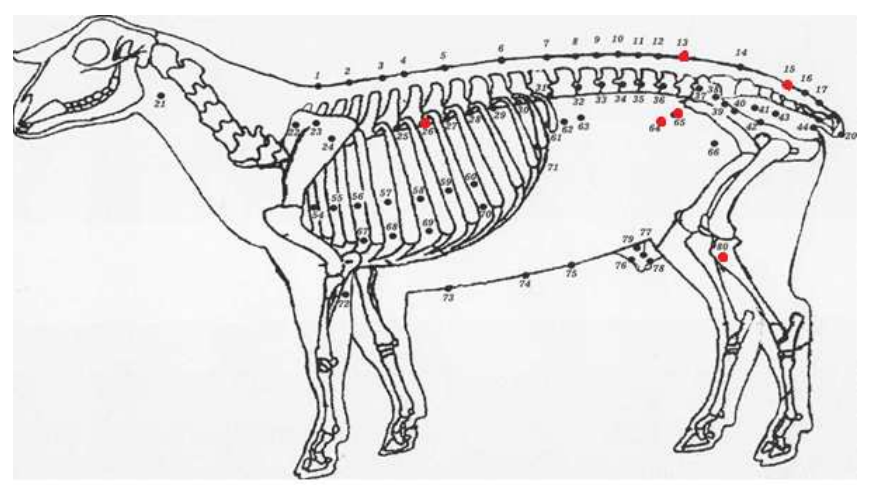

Figure 1. Osteolocalization of superficially localized biologically active centers on the body of sheep (side view) 


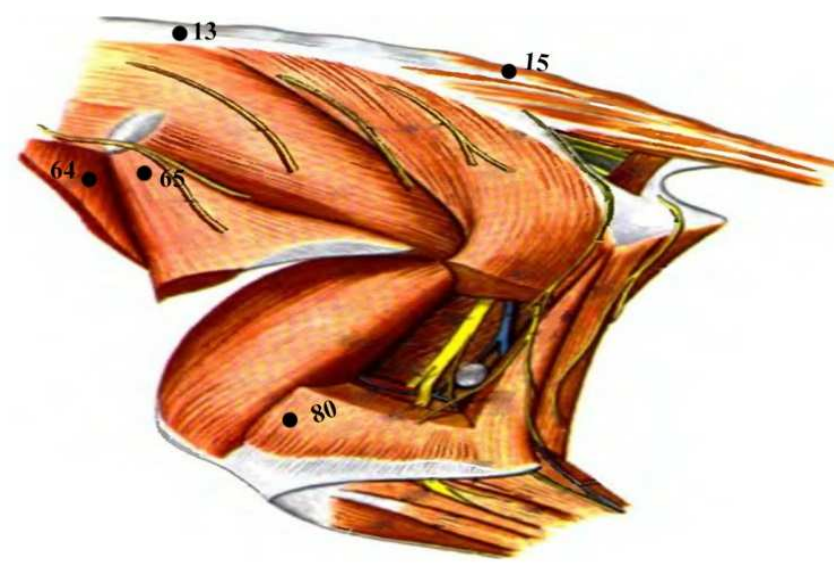

Figure 2. localization of SLBACs relative to the musculature of sheep (left view

The topographic search and measurement of the bioelectric potential level of SLBACs with an ELAPtype device (Russia).

The measurement of the level of bioelectric potential (LBP) of the SLBACs for assessing of the wool productivity was carried out during three adjacent days before the shearing job in the SLBACs №№ 13, 15, 64, 65,80 . After the shearing, $200 \mathrm{~g}$ wool samples were taken from different places. The following indicators were determined: wool clip, $\mathrm{kg}$; length of wool fibers, $\mathrm{cm}$; wool staple crimp, per $1 \mathrm{~cm}^{2}$ and elasticity, sec.

To determine the wool fineness, the measurement of the LBP of the SLBACs was carried out in the SLBACs No. 13, No. 26, No. 60, No. 65.

Wool fineness is the most important technological and selection indicator, which is determined at all stages of wool production, starting with the assessment of fiber on a sheep and ending with the wool yarn production and obtaining finished woolen products. Determination of the wool class was carried out by measuring the diameter of the cross-section of the wool fiber using microscopes in thousandths of a millimeter - microns $(\mu \mathrm{m})$.

According to the diameter of the wool fiber, fine and semi-fine wool is divided into 13 quality classes from 32 to 80, for each class of wool - quality, certain boundaries are set for the diameter of the wool fiber (fineness) in microns. For sheep of the North Caucasian breed of the Corriedale type, ewes have a wool class of 56-48 [16].

The research data were processed using biostatistical methods.

\section{Findings}

The obtained results, presented in Table 1, show that the bioelectric potential of the SLBACs in the ewe hoggs changed depending on the age and breed.

Table 1. Wool productivity of ewes depending on the level of the bioelectric potential of the SLBACs.

\begin{tabular}{|c|c|c|c|c|}
\hline & \multicolumn{4}{|c|}{ Ewe hoggs } \\
\hline & \multicolumn{2}{|c|}{$\begin{array}{l}\text { North Caucasian } \\
\text { (control) }\end{array}$} & \multicolumn{2}{|c|}{$\begin{array}{c}\text { Crossbred } \\
\text { (experimental group) }\end{array}$} \\
\hline & \multicolumn{4}{|c|}{ Age, months } \\
\hline & 6 & 8 & 6 & 8 \\
\hline$n$ & 3 & 3 & 3 & 3 \\
\hline $\begin{array}{l}\text { LBP of } 5 \\
\text { centers, } \\
\mu \mathrm{A}\end{array}$ & $34,3 \pm 0,2$ & $37,1 \pm 0,15$ & $\begin{array}{l}35,7 \pm 0,26 \\
* * *\end{array}$ & $\begin{array}{l}38,5 \pm 0,23 \\
* * *\end{array}$ \\
\hline \multirow{2}{*}{$\begin{array}{l}\text { Wool } \\
\text { clip, kg : } \\
\text { Grease }\end{array}$} & & & & \\
\hline & $1,20 \pm 0,2$ & $2,40 \pm 0,15$ & $1,17 \pm 0,26$ & $1,90 \pm 0,23$ \\
\hline $\begin{array}{l}\text { decrea- } \\
\text { sed }\end{array}$ & $0,54 \pm 0,2$ & $1,08 \pm 0,15$ & $0,52 \pm 0,26$ & $0,85 \pm 0,23$ \\
\hline $\begin{array}{l}\text { True } \\
\text { wool } \\
\text { length,cm }\end{array}$ & $13,6 \pm 0,2$ & $13,9 \pm 0,15$ & $\begin{array}{l}16,3 \pm 0,26 \\
* *\end{array}$ & $\begin{array}{l}15,0 \pm 0,23 \\
*\end{array}$ \\
\hline $\begin{array}{l}\text { Natural } \\
\text { wool } \\
\text { length, } \\
\mathrm{cm}\end{array}$ & $9,9 \pm 0,2$ & $11,4 \pm 0,15$ & $\begin{array}{l}14,4 \pm 0,26 \\
* *\end{array}$ & $\begin{array}{l}14,0 \pm 0,23 \\
* *\end{array}$ \\
\hline $\begin{array}{l}\text { Wool } \\
\text { staple } \\
\text { crimp, for } \\
1 \mathrm{~cm}\end{array}$ & $17,9 \pm 0,2$ & $20,1 \pm 0,15$ & $\begin{array}{l}20,0 \pm 0,26 \\
* *\end{array}$ & $\begin{array}{l}25,5 \pm 0,23 \\
* * *\end{array}$ \\
\hline $\begin{array}{l}\text { Elasticity, } \\
\text { sec }\end{array}$ & $4,0 \pm 0,20$ & $5,82 \pm 0,15$ & $3,9 \pm 0,26$ & $\begin{array}{l}4,9 \pm 0,23 \\
*\end{array}$ \\
\hline
\end{tabular}

Note: the difference is statistically significant in comparison with the control: * $\mathrm{P}>0.5 ; * * \mathrm{P}>0.01 ; * * * \mathrm{P}>0.00$.

A higher level of the biopotential was noted in the crossbred ewes at the age of six months old $-35.7 \mu \mathrm{A}$, which is $4.0 \%$ more than in the purebred sheep of the North Caucasian breed $(\mathrm{P}>0.001)$ at the age of 8 months old $-38.5 \mu \mathrm{A}$, which is $3 \%$ more than in the purebred sheep, with a significant difference $(\mathrm{P}>0.001)$. The manifestation of a higher level of the bioelectrical potential of the SLBACs in crossbred ewes is associated with better adaptive properties due to the structural and functional dominance of the physiological processes of the body of the crossbred animals and the internal interaction of the functional systems that carry out compensatory and adaptive reactions of the body.

Regardless of the breed, age-specific increase in the LBP of the SLBACs in the ewe hoggs of the experimental group was defined. The increase in the LBP of the SLBACs in the ewe hoggs of both experimental groups was on average by $2.8 \mu \mathrm{A}$.

The ewe hoggs of the North Caucasian breed with a low LBP of the SLBACs had a high wool clip. It was $1.20 \mathrm{~kg}$ at the age of six months old and $2.40 \mathrm{~kg}$ at the age of 8 months old with an uncertain difference with the animals of the experimental group.

In crossbred ewe hoggs at the age of 6 months old the difference with the control group in the true wool length was $2.7 \mathrm{~cm}(\mathrm{P}>0.01)$, the natural wool length was $4.5 \mathrm{~cm}(\mathrm{P}>0.05)$, wool staple crimp was $2.1(\mathrm{P}>$ $0.01)$. At the age of 8 months old, the differences relatively to the control group were $1.1 \%$ in the true length, $2.4 \%$ in the natural length, $5.4 \%$ in the wool staple crimp with a statistically significant difference. The elasticity figure of the wool fibers in the experimental groups did not have significant differences 
relatively to the control group. When comparing the measurement data of the LBP of the SLBACs No. 13, $15,64,65,80$ with the indicators of the sheep wool productivity, their direct proportional was established.

The fineness of wool in terms of its importance for technical use is the most important quality among all the other properties of wool fiber. To a certain extent, it also determines the value of wool productivity in connection with such characteristics as the density and length of wool, the size of the fleece, and it also characterizes the constitutional characteristics of sheep. Determination of wool fineness is necessary for a sheep farmer - breeder for proper selection of animals. Therefore, when evaluating sheep, it is one of the most important factors. Wool diameter also plays the role of a price factor, and, therefore, affects the profitability of the sheep breeding industry as a whole.

As a result of the research, a direct relationship between the LBP of the SLBACs and sheep wool classing (fineness) was established. 30 animal units of the purebred ewes of the North Caucasian breed were used in the research.

To determine the wool classing in all the experimental ewes the LBP was measured in SLBACs No. 13, 26, 60, 65; its average value was determined and the wool classing was studied. (Table 2).

It can be seen from the data in the table that all the experimental animals were divided into three groups according to the level of their biopotential. After conducting the laboratory studies, we obtained data on the fineness from 29 to $34 \mu \mathrm{m}$. When comparing the data on the wool fineness with the biopotential of the animals, a direct correlation between the LBP of the SLBACs and the sheep wool classing was established.

Table 2. Dependence of the wool classing of ewes on the LBP of the SLBACs

\begin{tabular}{|l|l|l|l|}
\hline Descriptors & \multicolumn{3}{|c|}{ Experimental group } \\
\cline { 2 - 4 } & 1 (control) & 2 & 3 \\
\hline $\begin{array}{l}\text { Number of } \\
\text { animals, units }\end{array}$ & 10 & 10 & 10 \\
\hline $\begin{array}{l}\text { LBP SLBACs, } \\
\mu \mathrm{A}\end{array}$ & $51,1 \pm 0,35$ & $60,3 \pm 0,40$ & $62,8 \pm 0,48$ \\
\hline Fineness, $\mu \mathrm{m}$ & $31-34$ & $29-31$ & $27-29$ \\
\hline Wool classing & 48 & 50 & 56 \\
\hline
\end{tabular}

Note: the difference is statistically certain in comparison with the control group: $* \mathrm{P}<0.05$; $* * \mathrm{P}<0.01$; $* * * \mathrm{P}<0.001$.

\section{Conclusions}

It has been established that the sheep of different breeds and ages have different LBP of the SLBACs, and the value of the biopotential can be used to assess the quantitative and qualitative properties of wool in the comparable units.

Based on the established dependencies, a method for determining a sheep wool classing has been developed. This method eliminates the need to use complex laboratory equipment and reduces the time for the wool research, which will lead to the intensification of breeding processes based on the scientific developments.

\section{References}

1. N.V. Ochkurova Bulletin of the Altai State Agrarian University. 2 (124), 60-64. (2015)

2. N.K. Timoshenko Sheep, goats, woolen business, 2, 9-14 (2013).

3. A. S. Erokhin Sheep, goats, wool business. 1, 3536, (2014)

4. V.I. Trukhachev, V.A. Moroz Zootechnics, 1(20), 28 - 30, (2010)

5. J. E. H. Niboyet, La moindre resistanse a lelectricite de surfaces punctiformeet de trajets cutanes concordant aves les «points et meridians $\gg$ bases de lacupuncture. (Marseille.1963)

6. J. E. H. Niboyet Letraitement des algies par l'acupuncture et centrains massages chinoises. (Paris, Lafitte, 1959).

7. P.K. Anokhin Philosophical aspects of the theory of functional systems. Selected Works. (Moscow, 1978)

8. G.V. Kazeev Veterinary acupuncture: monograph (Moscow, 2000)

9. A.V. Ryabukha Biological resources of the Russian Far East: international scientific practical. conf. Blagoveshchensk, P. 114-116. (2004)

10. K. A .Leshchukov Theoretical and practical aspects of the use of compensatory and adaptive reactions of agricultural animals for a comprehensive assessment and lifetime formation of product quality-abstract of the dissertation for the degree of Doctor of Agricultural Sciences, Kursk (2017)

11. A.V. Mamaev Theoretical and applied aspects of the use of the compensatory system of animals in assessing the functional state and stimulating the reproductive function - abstract of thesis for the degree of Doctor of Biological Sciences (Borovsk, 2005).

12. A.V. Baranov Achievements of science and technology APC 9, 21-23 (2011)

13. L.E. Orme Annals of N.Y. Acad. of Sciences. 110, 307-308, (1963).

14. E.M. Ross, A.G. Gilman Ann.Rev. Biochem., 533-564. (1980)

15. N.I. Verzhbitskaya Morphofunctional parameters of the acupuncture points and associated with them internal organs in different experimental conditions Theory and practice of reflexotherapy. (Saratov,1981)

16. Order of the Ministry of Agriculture of the Russian Federation No. 335 "On approval of the Procedure and conditions for appraising breeding sheep of fine-fleece breeds, semi-finefleece breeds and breeds of meat productivity". (2010) 